\title{
PENDUGAAN UMUR SIMPAN MENGGUNAKAN METODE ACCELERATED SHELF LIFE TEST (ASLT) MODEL ARRHENIUS PADA JAMU "SARI RAPET SUPER"
}

\author{
${ }^{1}$ Rika Diananing P, ${ }^{2}$ Ratih Yuniastri \\ ${ }^{1,2}$ Prodi. Teknologi Hasil Pertanian, Fakultas Pertanian, Universitas Wiraraja \\ email: rikadepe@wiraraja.ac.id
}

\begin{abstract}
ABSTRAK
Umur simpan adalah satu hal yang harus diperhatikan oleh konsumen dalam menggunakan suatu produk. Obat herbal adalah makanan fungsional yang sangat diminati oleh kebanyakan orang dan masih melekat dan merupakan obat tradisional yang berkhasiat dalam menjaga kebugaran fisik. Produk obat herbal yang beredar dan banyak diminati oleh konsumen, terutama wanita, adalah herbal "Sari Rapet Super". Tujuan dari penelitian ini adalah untuk memperkirakan umur simpan menggunakan metode Accelerated Shelf Life Test (ASLT) dengan model Arrhenius. Parameter yang digunakan adalah kadar air dengan perlakuan penyimpanan pada suhu 25, 35, 45 dan diamati pada hari $0,1,5,10,15,20$ selama satu bulan. Penyimpanan dengan kemasan dan tanpa kemasan. Hasil yang didapat, kadar air pada setiap suhu penyimpanan mengalami penurunan. Estimasi umur simpan dalam perlakuan perbedaan suhu dengan parameter kadar air tidak berpengaruh dan menghasilkan umur simpan untuk periode yang sama. Suhu 25 untuk = 34.82665831 ( 1 bulan 3 hari), suhu $35=$ 35.3338706 dan suhu $45=33.38062522$ sedangkan tanpa kemasan pada suhu $25=$ 10.98902468, suhu $35=9.598185153$, dan suhu $45=10,95095319$.
\end{abstract}

Kata kunci: Obat herbal, umur simpan, ASLT, Arrhenius

\section{ABSTRACT}

Shelf life is one thing that must be observed by consumers in using a product. Herbal medicine is a functional food that is in great demand by most people and is still attached to and is a traditional medicine that is efficacious in maintaining physical fitness. Herbal medicine products in circulation and much in demand by consumers, especially women, are "Sari Rapet Super" herbs. The purpose of this study was to estimate the shelf life using the Accelerated Shelf Life Test (ASLT) method with the Arrhenius model. The parameters used are the water content with storage treatment at temperatures 25, 35, 45 and observed on days 0, 1, 5, 10, 15, 20 for one month. Storage with packaging and without packaging. The results obtained, the water content at each storage temperature has decreased. Estimation of shelf life in the treatment of temperature differences with water content parameters is not influential and results in shelf life for the same period. Temperature 25 for $=34.82665831$ ( 1 month 3 days), temperature $35=35.3338706$ and temperature $45=33.38062522$ while without packaging at temperature $25=10.98902468$, temperature $35=9.598185153$, and temperature $45=10,95095319$.

Keywords: Herbal medicine, shelf life, ASLT, Arrhenius 


\section{PENDAHULUAN}

Umur simpan (kadaluarsa) pada produk pangan adalah wajib karena konsumen dapat mengetahui batas untuk mengkonsumsi produk tersebut. Pencantuman umur simpan pada produk pangan diatur dalam Undang-undang Pangan no. 7/1996 serta peraturan Pemerintah No.69/1999 tentang Label dan iklan pangan, dimana setiap industri pangan wajib mencantumkan tanggal kadaluarsa pada setiap kemasan pangan.

Jamu, salah satu pangan fungsional yang terbuat dari rempah serta memiliki khasiat bagi kesehatan tubuh. Rempah yang digunakan untuk pembuatan jamu yaitu semua jenis tanaman rimpang seperti kunyit (Curcuma domestica val), jahe (zingiber officinale), kencur (kaempferia galanga linn), lengkuas/laos (alpinia galanga), temuhitam (curcuma aeruginosa roxb), temuputih (C.zedoria), lemuyang gajah (Z. Zerumbet) dan masih banyak tanaman rimpang lainnya. Khasiat yang terkandung pada rimpang antara lain pati, pigmen, resin, lemak, gula, mineral serta senyawa metabolit sekunder termasuk didalamnya minyak atsiri, saponin, flavonoid, alkaloid, terpenoid dan steroid. Kandungan pada tamanan rimpang menurut penelitian (Sambara, 2016) menyimpulkan masyarakat ada daerah yang diteliti sebagian besar mengkonsumsi dan memproduksi tanaman rimpang untuk dimanfaatkan sebagai jamu. (Esti Nugraheni, 2010) dalam artikel pemanfaatan jamu kunyit asam pada mencit betina memiliki efek analgesik dengan formulasi yang sudah ditetapkan. Menurut (Arini, Ridla, \& Kristanto, 2016) dengan formulasi akan menimbulkan efek terhadap pertumbuhan dan perkembangan skeleton. Dalam (Purwaningsih, 2013) menyimpulkan dari analisis literatur Indonesia masih kurang konsisten terhadap penggunaan jamu, sehingga paten jamu lebih mudah dipatenkan di negara lain. (NURSIYAH, 2013) pada studi deskriptif pada jamu yang digunakan orang tua untuk jamu anak usia dini bukan hanya sebagai obat tradisional tetapi sebagai ramuan untuk menjaga kesehatan anak. Jamu merupakan minuman khas rempah yang memiliki khasiat terhadap tubuh. (Andriati, 2016) dalam artikel tingkat penerimaan konsumen terhadap jamu menyimpulkan daya terima terhadap jamu sekitar 58\%, hal tersebut dikarenakan masyarakat lebih mempercayakan jamu dalam penyembuhan penyakit.

Berdasarkan uraian tersebut dapat dirumuskan, bagaimana rempah dan tanaman rimpang dimanfaatkan untuk bahan baku jamu tradisional serta memiliki daya simpan dan dapat menjaga kesehatan masyarakat, baik dari anak anak sampai dewasa. Tujuan penelitian ini mengetahui umur simpan jamu dan menjaga khasiat jamu tersebut.

\section{METODE}

\section{Lokasi dan Waktu}

Penelitian dilakukan mulai bulan juni samppai bulan september 2019. Pengujian kadar air dan total mikroba di Laboratorium Pengujian Terpadu Universitas Pembangunan Nasional "Veteran" Jatim. Bahan menggunakan produk jamu yang diproduksi oleh Ny. Tus Ummi Kulsum yang beralamat di desa Bangselok Sumenep. 


\section{Tahapan Penelitian}

1. Menentukan suhu penyimpanan yang tepat

Penelitian ini menggunakan metode ASLT model Arrhenius. Pengujian dilakukan dengan menyimpan produk pada suhu 25 , 35 dan 45 c selama 20 hari dan dilakukan pengamatan pada hari ke- $0,5,10,15,20$ ppada setiap suhu penyimpanan. Penyimpanan jamu dengan menggunakan kemasan (K) dan tanpa kemasan (TK). Parameter yang diujikan menggunakan data kadar air. Penentuan umur simpan jamu "SARI RAPET SUPER" ditentukan berdasarkan umur simpan paling pendek diantara parameter kadar air.

Tabel 1. Kadar air selama Penyimpanan

\begin{tabular}{crrrrrr}
\hline & \multicolumn{2}{c}{$\begin{array}{c}\text { Kadar Air (\%) } \\
\text { (Kemasan) }\end{array}$} & \multicolumn{4}{c}{$\begin{array}{c}\text { Kadar Air (\%) } \\
\text { (Tanpa Kemasan) }\end{array}$} \\
\hline Hari & Suhu 25 & \multicolumn{1}{c}{ Suhu 35 } & \multicolumn{1}{c}{ Suhu 45 } & Suhu 25 & \multicolumn{1}{c}{ Suhu 35 } & \multicolumn{1}{c}{ Suhu 45 } \\
ke- & 8,89 & 8,89 & 8,89 & 8,89 & 8,89 & 8,89 \\
$\mathbf{0}$ & 8,73 & 8,76 & 7,76 & 8,5 & 7,6 & 6,86 \\
$\mathbf{1}$ & 8,6 & 8,5 & 7,5 & 8,45 & 7,45 & 6,75 \\
$\mathbf{5}$ & 8,06 & 8,04 & 7,4 & 8,3 & 7,35 & 6,65 \\
$\mathbf{1 0}$ & 8,02 & 8 & 7 & 8,01 & 7,27 & 6,5 \\
$\mathbf{1 5}$ & 7,89 & 7,8 & 6,9 & 7,95 & 7,01 & 6,31 \\
$\mathbf{2 0}$ & & & & & &
\end{tabular}

Sumber: data primer, 2019

Berdasarkan tabel 1, kadar air terhadap penyimpanan dengan kemasan dan tanpa kemasan memiliki nilai yang berbeda. Pada penyimpanan dengan kemasan perubahan yang terjadi pada suhu $45 \mathrm{c}$ dihasilkan penurunan. Hal ini disebabkan karena jamu tersebut dalam penyimpanan mengalami penguapan sehingga hilangnya kadar air. Keberadaan kadar air pada produk pangan akan menjadi faktor kritis, yaitu akan kehilangan mutunya pada saat hilangnya kandungan air. Menurut (Haryati, 2015) menjelaskan pada pendugaan umur simpan pada produk tape ketan,perubahan yang terjadi tidak berbeda signifikan karena pada awal penyimpanan
Jika mengikuti model laju kinetika ordo nol :

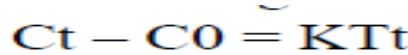

untuk laju reaksi mengikuti ordo satu adalah:

$\mathrm{Ln} C t=\mathrm{LnCO}+\mathrm{K} \times \mathrm{t}$

\section{HASIL dan PEMBAHASAN}

Hasil penelitian pendugaan umur simpan jamu dengan penyimpanan pada suhu 25 , 35,45 derajat celsius dengan lama penyimpanan selama 1 bulan. pengamatan dilakukan pada setiap suhu setiap hari ke$0,1,5,10,15,20$ sebagaimana tersaji pada Tabel 1 dibawah ini. penurunan kadar air sebanding dengan waktu penyimpanan dan kadar air akan konstan. Penentuan suhu yang tepat untuk penyimpanan percepatan adalah suhu yang digunakan diatas suhu penyimpanan normal sehingga memberikan hasil sesuai keinginan. Suhu yang digunakan juga tidak boleh terlalu tinggi karena akan terjadi penurunan produk. Menggunakan kemasan akan memberikan hasil umur simpan yang berbeda dengan tanpa kemasan. (Widyamurti, 2018) menjelaskan dengan kemasan akan berpengaruh terhadap pemasaran suatu produk dan (Cenadi, 2000). Data regresi yang 
Journal of Food Technology and Agroindustry Volume 1 No 2 Agustus 2019

P-ISSN: 2656-0623

E-ISSN: 2684-8252

diperoleh pada perlakuan pada parameter

kadar air yaitu pada tabel 2.

Tabel 2. Data Regresi

\begin{tabular}{lllcl}
\hline & \multirow{2}{*}{ Kemasan } & \multicolumn{1}{c}{ Tanpa Kemasan } & \multicolumn{2}{c}{ R2 } \\
\cline { 4 - 5 } & & & Kemasan & Tanpa Kemasan \\
\hline suhu 25 & $y=-0.0057 x+2.1732$ & $y=-0.0081 x+2.0923$ & $R 2=0.8807$ & $R 2=0.5969$ \\
suhu 35 & $y=-0.0065 x+2.1744$ & $y=-0.0092 x+2.1801$ & $R 2=0.9414$ & $R 2=0.8415$ \\
suhu 45 & $y=-0.0099 x+2.105$ & $y=-0.011 x+2.0319$ & $R 2=0.7387$ & $R 2=0.5$ \\
\hline
\end{tabular}

Sumber data primer 2019

Analisis regresi selama ppenyimpanan

masing-masing suhumemberikan nilai $\mathrm{E} / \mathrm{R}$ menunjukkan nilai $\mathrm{k}$ sebesar 0,0516 pada sebesar $-7,9185$ dan $\mathrm{k} 0$ sebesar 26,3956 suhu $25^{\circ} \mathrm{C}$, pada suhu $35^{\circ} \mathrm{C}$ sebesar 0,0484, dan 0,0444 pada suhu 45c. Plot sehingga diperoleh hasil sebagaimana pada Arrhenius berdasarkan nilai $\mathrm{k}$ pada gambar 1.

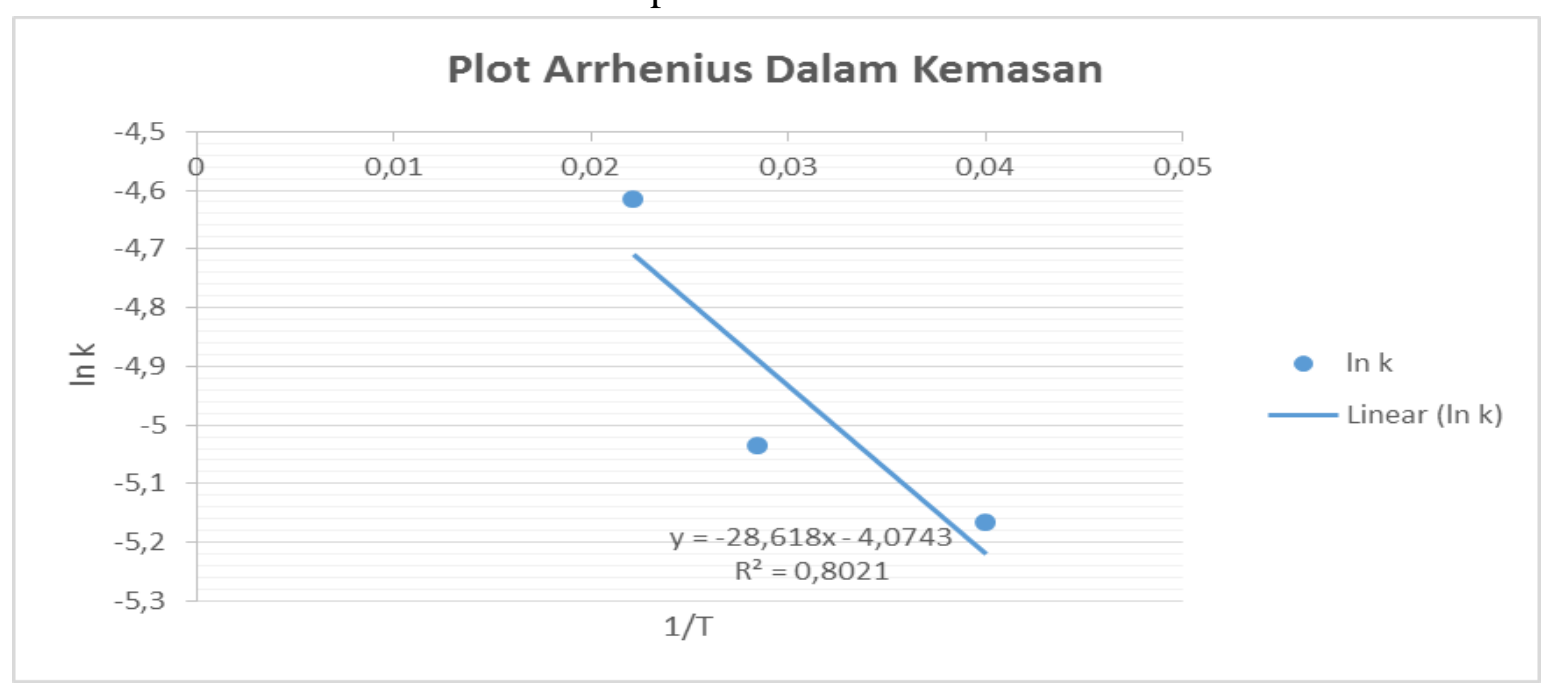

Gambar 1. Plot Arrhenius Jamu dalam Kemasan

Plot Arrhenius dengan kemasan menghasilkan laju pada kadar air, maka dapat menentukan kadar kritis yang dihasilkan adalah 9,43. Sedangkan pada jamu tanpa kemasan menghassilkan laju pada kadar air dengan kadar kritis 9,03. Pada gambar 2 plot Arrhenius jamu tanpa kemasan dengan perhitungan umur simpan $\mathrm{y}=-16.444 \mathrm{x}-4.1743 ; \ln \mathrm{k}(-4,1743)$ dan $\mathrm{k}$ $(0,015386)$.

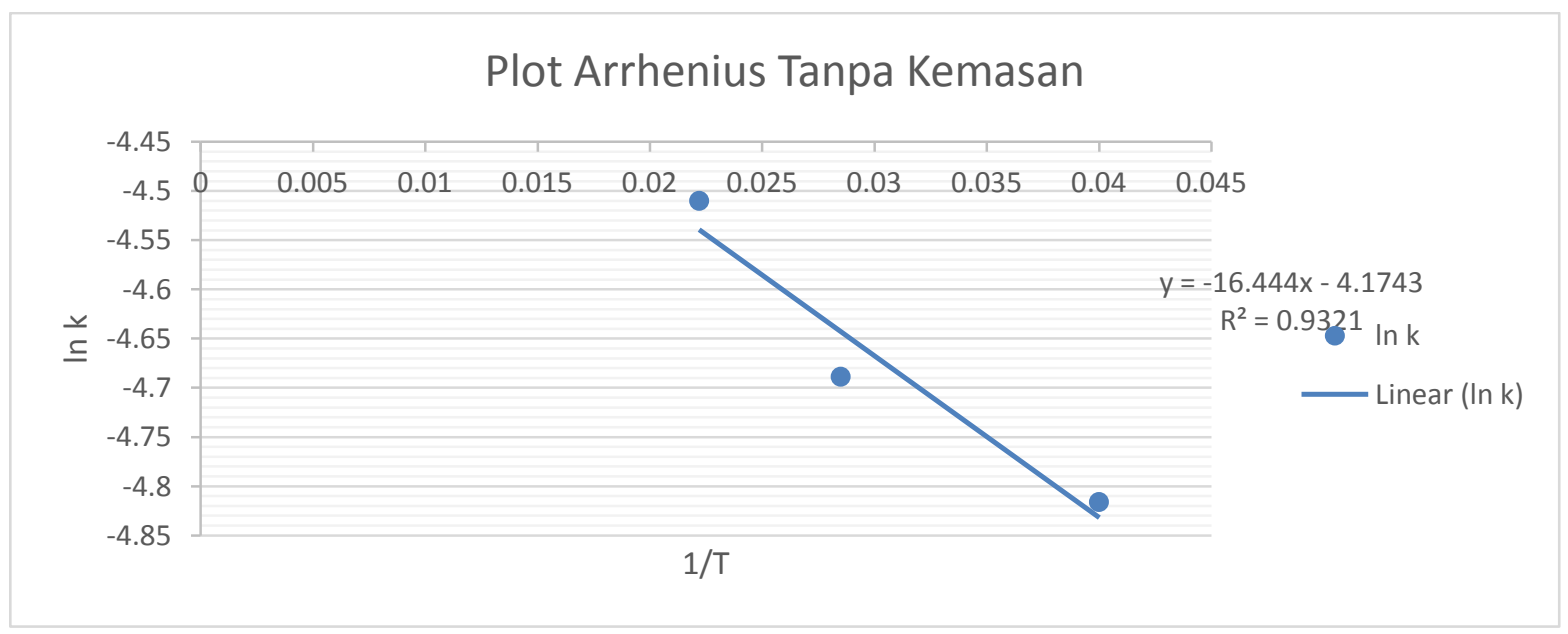

Gambar 2. Plot Arrhenius Tanpa Kemasan 
Dalam (Hapsari, 2014) pada perlakuan pendugaan umur simpan crakers memiliki kadar air 5\% sedangkan untuk jamu menurut (MENTERI KESEHATAN, 1994) bahwa jamu memiliki kadar air dibawah $10 \%$.

Pendugaan umur simpan pada jamu dengan merk dagang "Sari Rapet Super" suhu 25 selama $=34,82665831$ ( 1 bulan 3 hari), suhu $35=35,33820706$ dan suhu $45=$ 33,38062522 sedangkan tanpa kemasan pada suhu $25=10,98902468$, suhu $35=$ 9,598185153, dan suhu $45=10,95095319$. Hasil yang diperoleh untuk pendugaan umur simpan, bahwa perlakuan perbedaan suhu 25 , 35,45 derajat celsius pada penyimpanan jamu dengan kemasan ataupun tanpa kemasan tidak berpengaruh terhadap lama penyimpanan.

\section{KESIMPULAN}

Perlakuan pendugaan umur simpan dengan parameter kadar air, pada perbedaan suhu penyimpanan $(25,35,45)$ tidak berpengaruh terhadap lama penyimpanan karena pada ketiga suhu tersebut menghasilkan umur simpan yang sama.

\section{DAFTAR PUSTAKA}

Andriati. (2016). Tingkat penerimaan penggunaan jamu sebagai alternatif penggunaan obat modern pada masyarakat ekonomi rendah-menengah dan atas Society' $s$ acceptance level of herb as alternative to modern medicine for lower, middle , and upper class group. Masyarakat, Kebudayaan Dan Olitik Vol.29, No. 3, Tahun 2016, 29, 133-145.

Arini, A., Ridla, L., \& Kristanto, H. (2016). PENGARUH PEMBERIAN EKSTRAK KUNYIT ASAM (
Curcuma domestica - Tamarindus

indica ) TERHADAP

PERTUMBUHAN DAN PERKEMBANGAN SKELETON FETUS MENCIT BALB / C DALAM PERIODE GESTASI. Jurnal Kedokteran Diponegoro, 5(4), 246-257. Cenadi. (2000). PERANAN DESAIN KEMASAN DALAM DUNIA PEMASARAN. NIRMANA, 2(1), 92103.

Esti Nugraheni. (2010). Efek dan daya analgesik jaтu kunyit asam ramuan segar komposisi 20,7\%: 9,3\% pada mencit betina.

Hapsari. (2014). Penerapan metode accelerated shelf life testing (aslt)arrhenius untuk konfirmasi umur simpan produk biskuit. Tugas Akhir. Haryati, ett all. (2015). PENDUGAAN UMUR SIMPAN MENGGUNAKAN METODE ACCELERATED SHELFLIFE TESTING ( ASLT ) DENGAN PENDEKATAN ARRHENIUS PADA PRODUK TAPE KETAN HITAM KHAS MOJOKERTO HASIL STERILISASI Shelf- Life Prediction of Sterilized Mojokerto 's Fermented Black Glutinous Rice Us. Jurnal Pangan Dan Agroindustri Vol. 3 No 1 p.156-165, Januari 2015, 3(1), 156165.

MENTERI KESEHATAN. (1994). MENTERI KESEHATAN REPUBLIK INOONESIA KEPUTUSAN MENTERI KESEHATAN REPUBLIK INDONESIA NOMOR : 661/MENKES/SK/VII/ 1994 TENTANG PERSYARATAN OBAT TRADISIONAL.

NURSIYAH. (2013). STUDI DESKRIPTIF TANAMAN OBAT TRADISIONAL YANG DIGUNAKAN ORANGTUA UNTUK KESEHATAN ANAK USIA DINI DI GUGUS MELATI 
Journal of Food Technology and Agroindustry Volume 1 No 2 Agustus 2019

P-ISSN: 2656-0623

E-ISSN: 2684-8252

KECAMATAN KALIKAJAR

KABUPATEN WONOSOBO.

Purwaningsih, E. H. (2013). Jamu, Obat

Tradisional Asli Indonesia Pasang Surut

Pemanfaatannya di Indonesia, 1(2).

Sambara. (2016). PEMANFAATAN

TANAMAN OBAT TRADISIONAL

OLEH MASYARAKAT

KELURAHAN MERDEKA

KECAMATAN TIMUR 2016. Jurnal

Info Kesehatan, Vol 14 Nomor 1 Juni

2016, 14, 1113-1125.

Widyamurti, N. (2018). STANDING

POUCH BERBAHAN PAPER METAL

DI ERA EKONOMI. Jurnal Industri

Kreatif Dan Kewirausahaan E-

ISSN:2620-942x, 1(1), 1-9. 